\title{
Mediatization, Spatial Coherence and Social Sustainability: The Role of Digital Media Networks in a Swedish Countryside Community
}

\author{
By André Jansson
}

\begin{abstract}
What does the implementation of new communication networks mean for the spatial coherence and social sustainability of rural communities? This paper takes its key from Wittel's discussion of network sociality, understood as the opposite of Gemeinschaft. Wittel's argument may inform our understanding of how communicative patterns in rural communities are partly re-embedded through ongoing media transitions. But it must also be problematized. Relating Wittel's discussion to Halfacree's model of spatial coherence and Urry's notion of network capital, as well as to findings from an ethnographic study in a Swedish countryside community, a more complex view is presented. It is argued that global communication networks under rural conditions contribute to the integration and sustainability of the community, as much as to processes of expansion and differentiation. The results show that network sociality and community constitute interdependent concepts. Through their capacity of linking people to external realms of interest, while simultaneously reinforcing their sense of belonging in the local community, online media promote ontological security at the individual level, thus operating as a social stabilizer.
\end{abstract}

Keywords: Media, rurality, community, networks, space, network capital 


\section{Introduction ${ }^{1}$}

The overarching aim of this article is to provide an empirical and theoretical account of the social role of information and communication technology (ICT) networks for the production of a global countryside. This particular notion of rural change has been stated within rural studies during the last decade, but it attains a focus on social and economic processes rather than on media and communication. Nonetheless, there are a growing number of articles that underscore the role of new networks in a broader sense (see especially Woods 2007) and thus implicitly highlight the need for rural media studies. As a contribution to the development of such a research field, this study seeks chiefly to ascertain whether the ongoing production of a global, networked countryside implies a growing sense of spatial coherence, following Keith Halfacree's (2006) Lefebvrian model, and sustainability, or leads to increasing disintegration. Based on qualitative interview data from a Swedish countryside community, it will be argued that the former scenario is the more likely consequence of rural mediatization.

The article begins with a theoretical discussion of how mediatization might affect the spatial coherence of the global countryside, and more specifically, whether the expansion of new forms of network sociality, defined by Andreas Wittel (2001) as the opposite of community, constitutes a potential threat to the social sustainability of rural areas. Next, presenting the empirical results from the Swedish countryside community of Granby (a fictive name) (where the expansion of new networks is an ongoing social and political issue) the article addresses the symbolic role of ICT networks in maintaining a coherent community image and narrative, as well as the social significance of possessing what John Urry (2007) calls network capital.

\section{Studying Mediatization and the Global Countryside}

In a recent article, Michael Woods (2007) suggests ten defining criteria of the global countryside: (1) dependence on elongated commodity networks; (2) corporate integration with transnational networks; (3) exposure to (global) migrant labour; (4) exposure to global tourism; (5) non-national property investments; (6) discursive commodification of nature; (7) containing commercially exploited landscapes; (8) increasing social polarization; (9) new sites of political authority (e.g. the World Trade Organization); and (10) collisions of interests, resulting in social and political conflicts regarding the development of rural spaces. While these ten characteristics together "reflect an idealized condition of global rural integration" (ibid: 494), their more exact implications must be studied at particular sites and in relation to their particular historical contexts. Accordingly, sitespecific amalgamations (or hybridizations) of the processes suggested by Woods produce a multitude of global countrysides. 
While the significance of the media and new ICT networks is not explicitly listed here, the expansion of such institutions and networks is clearly given as a precondition for several of the other processes. As Woods puts it, what is new about this particular stage of rural transformation "is the intensity and immediacy of the global networks of connections and flows into which rural localities may be enrolled" (Woods 2007: 500). Furthermore, there is a representational dimension to the role of media and ICT networks, according to Woods. Through discourse they produce the imaginary structures of rural spaces and places, which are in turn "conveyed through global networks, such that certain rural locations acquire a global significance in that they are known and have meaning in contexts geographically distant from the locality" (ibid: 501). I will, in this article, use the term mediatization to analyze the role of the media within this kind of social reembedding processes (Giddens 1991). The term mediatization refers to a complex process through which the media (institutions, technologies and representations) disembed social practices and experiences, while simultaneously making these practices and experiences dependent upon the media as such, which means that a new kind of embeddedness is taking shape (see Lundby 2009, for an extended discussion of the mediatization concept).

For those who want to pursue the kind of situated explorations of the global countryside that Woods propagates, understanding the social dynamics of mediatization is a quintessential task. Such explorations, I argue, must be both critical and multidimensional. By "critical" I mean that rural media studies must try to engage with the ideological battles that surround the mediatization of the countryside, especially when it comes to detecting those dominant discourses that reproduce given "truths" about the consequences of new media. For instance, critical studies must not pertain narrowly to either a metaphysic of flow (nomadism) or a metaphysic of fixity (sedentarism) (see Cresswell 2006, for an account of these competing metaphysics). Full access to new media networks can never be a panacea for threatened rural forms of production nor sociality; nevertheless, a number of potentials can be opened-up (see Park 2004, for a visionary account). In addition, it cannot be assumed that "genuine" rural places and ways of life, seen from the sedentary view, will be swept away by media-sustained forms of postproductivism (see Halfacree 2007, for various scenarios of post-productivism). Social realities tend to unfold somewhere in between these two extremes in relatively contradictory ways.

This is also why rural media studies must be multidimensional. The best way to analytically grasp the spatial multidimensionality of mediatization, I suggest, is to apply Henri Lefebvre's (1974/1991) triadic structure of social space. According to his viewpoint, the complexity of spatial production depends upon the interplay between (1) people's activities in material landscapes (perceived space); (2) the circulation of spatial representations (conceived space); and (3) spatial imageries in the shape of ideologies, myths, and so on (lived space). A full understanding of 
any given space can be reached only when these three realms are analytically inter-connected. This, in the case of rural media space, means that one must attend to (1) material media infrastructures; (2) media representations (whether development plans, place marketing, or popular culture); and (3) lived media experiences and imageries. Furthermore, one must attend to how these are embedded in various ideological formations (see also Jansson and Falkheimer 2006). A similar three-fold model, inspired by Lefebvre, is suggested from a rural studies perspective by Keith Halfacree $(2006 ; 2007)$, who argues that rural space must be interpreted as a processual entity evolving through the relationship between three constitutive realms: (1) rural localities, (2) formal representations of the rural, and (3) everyday lives of the rural. Although Halfacree does not provide any separate account of media and communication, it is quite axiomatic that, as shown above, mediatization affects all three spheres.

An integrated triadic model of rural media space will help us to articulate the ways in which mediatization contributes to the production of a global countryside as understood, for instance, in terms of the ten key features listed by Woods. Moreover, it will show to what extent such mediatized processes involve conflicts and ruptures between (and within) the three spaces. Halfacree (2007: 127-8) points out that one might then distinguish different formats of a rural coherence from one another, based on whether a certain region or place is marked by congruence and harmony between the three spaces; or at the other extreme, chaos and incoherence. He states that: "In a congruent and unified coherence, with localities, representations and everyday lives internalizing each other, a clear degree of stability is suggested, at least in terms of spatiality; what is conceived is perceived is lived" (ibid: 128).

Following this Lefebvrian framework, I will in this article pay particular attention to how new global media networks affect rural everyday lives and the people's understanding of their own local municipality. A key-question therefore addresses the level of coherence persisting in the area under study. I will argue that the access to and the use of new media networks have a significant positive impact upon the level of spatial coherence. I will also argue that this coherence, in turn, is an important indicator of social sustainability. By social sustainability I am referring to the enduring potential of a particular community to maintain the social and cultural interests of its inhabitants, including equal access to various services; good opportunities for political and cultural participation, expression and integration; and an enduring sense of community. Social sustainability, which has been adapted in similar ways within rural studies (see e.g. Scott et al 2000; McKenzie 2004), can thus be analyzed through the triadic model of spatial production and points to a particular balance between social continuity and change.

My key point is that the new socialities, which are enabled through ICT networks, are crucial for maintaining a sense of social continuity. I will thus problematize some of the ideas on the expansion of network society which have invoked 
an opposition between network sociality and community (see especially Wittel 2001). Before turning to my empirical data, I will briefly present the theoretical discussion which implicitly suggests that the implementation of ICT networks and social media, particularly in rural areas, would lead to incoherence and conflict.

\section{Rurality Versus Network Sociality}

The division between the city and the countryside - between urban and rural overlaps with other fundamental social dichotomies, such as global versus local; flow versus fixity; and transition versus tradition (cf Cresswell 2006). As several theorists have pointed out, this division is deeply rooted in modern history. It also has a tendency to get reproduced through mediated public discourse in which the countryside, in general and in terms of particular locations, is typically understood as either a romantic idyll or a rigid backwater (see e.g. Bunce 1994; Fish 2005; Short 2006; Juska 2006; Cruickshank 2009). This imaginary structure was statistically confirmed in a recent Swedish survey. While city life among the Swedish population connotes more cosmopolitan characteristics such as openness and global engagement, the countryside is associated with for instance solidarity and local engagement (see Jansson 2009a). In other words, the people's understanding of the countryside conforms to Ferdinand Tönnies' (1887/2001) classical concept of Gemeinschaft, which is a particular type of social communion that stands in opposition to both modern ways of administrative social organization (Gesellschaft) and social modes that more recently have been associated with network society.

In this context, I want to pay particular attention to Andreas Wittel's (2001) discussion of network sociality, which he explicitly defines as counterposed to Gemeinschaft. According to Wittel, who is inspired by thinkers such as Giddens and Castells, social organization is disembedded in the information age (in which knowledge and experiences are exchanged through globalized networks). "Networking" becomes a key social practice which occurs more and more often over large distances and which implies that social relations become more fleeting, transient and commodified. However, it must not be understood as a general and evenly distributed phenomenon. Wittel stresses that the rise of network sociality is especially visible in urban (post)industrial spaces and among the new middle classes of media and computer-literate people (ibid: 53). Network sociality is thus an emergent social mode, an aspect of mediatization, that negates the lived space of "rurality as Gemeinschaft", both conceptually and demographically.

This does not mean that Wittel's analysis is entirely pessimistic. He does not argue that network sociality automatically eliminates the social significance of Gemeinschaft or that network sociality is something inherently bad as such: "Instead of perceiving this process as de-socialization, I suggest a shift away from regimes of sociality in closed social systems and towards regimes of sociality in 
open social systems" (ibid: 64). This would also imply a shift away from those community forms based on what Robert Putnam (2000) calls strong ties (relations marked by reciprocity, trust and mutual obligations), towards those based on weak ties (more loosely associated networks). Putnam argues that strong ties condition the accumulation of social capital, since people's ability to successfully pursue joint projects must always rely on a sense of personal trust and a shared knowledge horizon. Such conditions are, according to him, foremost at hand in small scale communities - an argument that has been articulated also in public debate, e.g. by the Slow City movement.

In what way does the potential expansion of network sociality affect rural settings? While Wittel's analysis revolves exclusively around the urban classes that were up-and-coming at the turn of the millennium, almost a decade later the spread of mobile telephones and the popular use of networking platforms (such as Facebook, MySpace, Twitter, etc) ask us to broaden his research scope. We must direct our attention to society at large, including the most remote and most recently connected regions of society, in order to grasp what the social intersection of traditional communities (closed systems) and an expanding order of network sociality (open systems) may look like. The empirical results below suggest that once we take a closer look at concrete sites of rural life, we find that network sociality often is a much more complex and socially embedded phenomenon than Wittel's study suggests. This is not only because the empirical setting is different from the one that he studied, but also because there are certain components within the logic of network sociality that nurture, and are nurtured by, social proximity and trust. John Urry's (2007) concept of network capital, which I will return to later on, is useful for apprehending how new technological networking resources in countryside regions may contribute not only to network sociality, but also to social capital, a sense of stability and spatial coherence. This occurs at two principal levels: firstly, at the level of local community maintenance for which the very introduction and appropriation of new infrastructures may enhance the sense of symbolic and social integration; and secondly, at the level of social agency and everyday life in which network sociality may actually evolve through ritualized social practices, which hold a time-binding function and contribute to the individual's sense of ontological security. While these two levels are mutually dependent, testifying to the complexity of mediatization, I will discuss them separately for the sake of clarity.

\section{Community: ICT Networks as a Symbol of Continuity and Integration}

The current research has taken place in a small countryside community in the region of Värmland, Sweden. The region is located at the same latitude as Stockholm and Oslo and borders Norway. I have chosen to use fictive names through- 
out this analysis, calling the community Granby and the broader municipality Storvik. The study is based on qualitative interviews with ten persons who live and work in the area, as well as several periods of ethnographic observation. ${ }^{2}$ Four of the informants have been interviewed in their professional capacities as leaders and administrators within the local authorities. The rest of the interviewees have participated as residents.

The municipality of Storvik has been, and still is, dependent on a few mechanical industries. It has been heavily affected not only by the general transitions of (post-) industrial society, but also by the economic crisis that began in 2008 . However, the Storvik municipality is well-known for its rich cultural heritage and attractive surroundings. It hosts several major cultural events, especially during the summer season, and is a popular shopping destination among Norwegian visitors. Granby is marked by the transition from traditional forms of production to a more service oriented, or "post-productivist", economy (Halfacree 2007), involving for instance wilderness tourism and innovation industries. Compared to many other similar countryside communities, Granby has experienced a positive development during the last decade due to increasing tourism and the establishment of successful businesses. While the entire community was under threat around the turn of the millennium, when several local services closed down, the situation has stabilized. The school has expanded, and the area is catching up with infrastructural developments. People in the central parts of the community have broadband access, and the mobile network covers a growing area. However, this does not mean that the new digital networks reach all inhabitants. There is still a split between people within the reach of ICT networks and those beyond. The boundary in regards to the mobile coverage is fleeting, but when it comes to broadband there is a distinct split between those who have access and those who have not.

The transition of Granby can thus be understood through a combination of factors that affect both social structures and the population's sense of belonging. Ronny Johansson, who is the chairman of the Storvik municipality council, points to this interplay in terms of a new "mental position", but he also stresses the key role played by mediated symbolic components.

Ronny Johansson: Previously, when a new entrepreneur came to Granby people
were skeptical - they did not expect anything else than "yet another fucking allow-
ance applicant". But now when people see what has happened they have raised their
shoulders and heads in a fantastic way. "We are indeed something." It shows how
different phases affect people and people's reactions. [...] Ten years ago the attitude
was extremely negative out there. [...] People's mental position changes, and that is
very important when thinking of the media and its role. [...] It is very easy to make
the media write about economic cuts and misery, but when it comes to new em-
ployment and new opportunities, it is much more difficult to get the conversation
going.

The affirmative community narrative of Granby has found its way into local and regional news media and has gained a much deeper significance than ordinary political clichés or media management formulas. The story is vividly retold by the 
rest of my informants, and the strength of the story is reinforced by the fact that many people characterize change as an outcome of both fortunate coincidences (unexpected new industries) and collective work, rather than of "artificial" political programmes. Social change is thus understood as "real change" and something that people want to identify with. The expansion of broadband and mobile telephone networks is a case in point and has evoked civic engagement at various levels. Different actors, both private and corporate ones, have tried to bring about this development during a long period of time; and they have succeeded to a great extent. However, there are still people and businesses "on the border" whose interests are too expensive to satisfy, both for the municipality and for private telecom companies. Under such conditions it becomes obvious how the realization of new infrastructure affects people's overarching sense of spatial coherence. For instance, the tourism business of the wilderness camping in Fors (a small community some miles away from the centre of Granby) is in great need of digital networks but must still operate under highly ambivalent conditions. Nina Eklund, the director of the wilderness camping, points out that insufficient ICT networks lead to a perceived lack of services among their customers.

Nina Eklund (director): Mobile coverage... we get lots and lots of questions about why it doesn't work as it should. Last year it got better when they set up three new masts in the area, but unfortunately they don't cover Fors, and that's where our guests are most of the time. It's crazy! We have been writing for years about this, mentioning our work needs and also the security of our guests if there are accidents in the forests. [...] Now when they set up these masts, we thought that it would cover enough, but not Fors [...] it's a disaster. Obviously the mast is too low!

These conditions threaten the long-term sustainability of Fors as a whole. Firstly, if there is no broadband connection (which there is not yet), the main office (including booking administration, marketing, etc) cannot be moved to Fors but has to stay in its present location in Storvik. It will also not be possible to make wilderness tourism a year-round business, even though such a development is much requested. Secondly, most guests are international (coming from Germany, Denmark, and the Netherlands), and their demands for wireless internet service and mobile coverage on the campground are steadily increasing. Altogether, Nina Eklund's statement points to an enduring sense of dissonance between ambitions and resources - an experience of being somehow marginalized within the overall narrative of the Granby community. The general mediatization of society has thus resulted in a sense of lack at the local level, which could even be seen as an integral component of mediatization as such. The situation is also paradoxical from a spatial point of view; while wilderness tourism generates global mobility of people and information, those in charge of the business can neither develop their market concept as they would prefer, nor keep up their work at the very "site of production".

In my material there are also examples of how the practical and symbolic appropriation of new communications infrastructure corresponds to an increased 
sense of local belonging and integration. Erik, who lives with his family in an old house beyond the limits of the broadband network, describes a long period of fruitless battles with the municipality representatives. Erik and his neighbor, John, eventually made contacts with a private company that is developing a new analogue transmission system for mobile networking. Starting out as test pilots for this new system, the households of Erik and John now have permanent access to the internet and other networking services.

Erik: We were among the first who got this, so then we skipped the local authorities. Instead we could be part of building up this new system. John, who is a real enthusiast, was in contact with the company director almost every week in order to increase the speed of the connection. The boss even went here to study our specific conditions, because they were so unique. [...] Previously John and I had even said that we could have dug down the cable ourselves, because I can get hold of an excavator, and those [other households] who wanted to connect along the way could have done that.

This example characterizes the cooperative tradition and do-it-yourself culture that flourishes in many rural areas. During the past years, there have been a great number of similar cases in Sweden. Rural interest groups have "rolled out" the cables themselves and thus ensured more equal access to the new means of communication where the local authorities had failed to do so. Similar events have taken place earlier in history, for example, during the first years of the telephone era in the late $19^{\text {th }}$ century America. News reports from that time and context describe how farmers sometimes created local neighborhood networks by using the middle-wire of pre-existing barbed wire fences. Many of these local networks were eventually connected to main lines and large companies (see Kline 2000; Zimmerman Umble 2003). There are also similar examples from more recent times (see Green's article in this journal issue). As shown by the interview extract above, the experience of having found one's own solution to the problem of connectivity contributes to a sense of local pride and becomes a symbolic confirmation of local sustainability in times of social transition.

An important point here is thus that the very quest for obtaining access to networks reinforces a shared identity and commitment among those households and entrepreneurs which are located beyond the regular networks. Furthermore, in successful cases like the one just mentioned, collaborative efforts have wider consequences than the reproduction of social capital; they lead to practical consequences such as new opportunities for carrying out private and professional duties at-a-distance. As will be shown in the forthcoming section, these new opportunities may actually affect people's decision to remain in geographically "peripheral" regions. 


\section{Everyday Life: The Integrating Force of Networking}

Moving to the theoretical level of everyday life, there are two points I want to make in regards to the role of new communication networks in rural areas. Both points entail a problematization of Wittel's (2001) argument as to the rise of network sociality. While my first point (a) is to prove the usefulness of network capital as a term for grasping how new ICT networks contribute to spatial coherence, my second point (b) highlights the time-binding role of network sociality.

\section{(a) The Key Role of Network Capital}

As shown in the previous section, among the people I have interviewed, social capital is a prevailing resource that ties the individual to the local context. Most interviewees are also active in local organizations and interest groups related to, for example, sports, music and religious matters - a condition that further express the commonalities between their identities and Putnam's understanding of social capital. The rise of new mediated forms of interaction has clearly affected the ways in which this local orientation is embedded, also involving the potential for network sociality, that is, contact making within open social systems. However, in the rural setting the social mechanisms and implications are not as clear-cut as in the urban area that Wittel (2001) studied. Among my interviewees, the social role of new media is constituted through a process in which network sociality interweaves with the acquisition and expression of social capital. Network sociality is thus integral to community building at the local level. The following extract from my interview with Thomas, who plays in a band with members from the wider municipality of Storvik, provides a good illustration.

\footnotetext{
Interviewer: How do you use the Internet?

Thomas: Email is very much used, partly for communicating with the others in the band, and we also have a MySpace page that we maintain. And then... for a while it was much downloading of movies, and now I have discovered Spotify, if you know what that is, and I'm all excited! I can put on exactly the music I want to hear. And browsing through different radio stations is also a very nice thing about the internet, I think. [...] We've gotten a lot of friends through MySpace... It's very good to have that page which we can refer to. And people can go in there and have a look. [...] It's a contact network. Soon we'll give a concert at Royal, and before that we can communicate through MySpace.
}

Thomas's glocal repertoire of online practices highlights the problem of analytically separating network sociality from community. As John Urry (2003) argues in his discussion of the relationship between networking and meetings, these two forms of interaction are not substitutable but tend to reinforce one another within the process of mediatization. More networking in general means more meetings, whether we look at the local community level or at the wider geographical context. Similarly, John Tomlinson $(1999,2001,2008)$ points out that it is problematic to believe that people lose their general sense of local community only because they start using a wider range of communications media. Tomlinson en- 
courages us to also consider the opposite viewpoint: many new media (perhaps especially networked ones) operate as "technologies of the hearth", through which close relations are maintained rather than challenged (Tomlinson 2008: 67-8; see also discussion in Morley 2007: Ch. 7).

The interview with Thomas also shows that the dual potential of online media (to operate simultaneously as "technologies of cosmos" and "technologies of the hearth") is realized only through a process of social shaping, that is, through the exercise of a particular habitus and lifestyle, which this kind of technology both reproduces and is culturally defined through (see Bourdieu 1974/1984, on the cultural mechanisms of social classification). At the structural level we may conclude that increasing internet access in rural areas affects the likelihood for people with a more cosmopolitan outlook (like Thomas) to nurture and exercise their interests. It further enables them to sustain bonds with others who may not be located within the immediate proximity, but in the adjacent regional context. Accordingly, the centrifugal impetus of networking (partly articulated through different forms of network sociality) may encourage people to stay where they are and to become more deeply involved in their local communities instead of moving to more central areas or nodes. This can also be understood as a socially extended consequence of the phenomenological "doubling of reality", or "doubling of place" (Scannell 1996; Moores 2004, 2008), which the media enhance.

At this point John Urry's (2007) concept of network capital becomes useful. It helps one to understand the intermediary, stabilizing role of digital networks and especially social media. Network capital refers to all those resources that enable people to move and make contacts in smooth and controllable ways, notably in the global context. Expressions and sources of network capital are, for instance, efficient communication devices, appropriate travel documents and visas, as well as access to convenient meeting places. What makes network capital such a useful concept is its dynamic nature. Firstly, network capital entails a dual movement between separation and integration. The possession of network capital refers to a capacity of letting go and to integrate with distant others, while not being forced to do so. In contrast to social capital, Urry (ibid: 200) argues that "the more general concept of network capital brings out how co-presence and trust can be generated at-a-distance". The concept thus bridges the epistemological gap between network sociality and community.

Secondly, network capital is not merely about mobility as such, but just as much about the experience of being potentially mobile and connected. While grounded in very concrete spatial resources (Lefebvre's perceived space), network capital largely operates through spatial imagination and experience (Lefebvre's lived space). Even though a person like Thomas may not be a frequent traveler, access to global communication networks enhances his sense of connectivity and global orientation (even "exitability" (ibid: 201)) and thus his sense of possessing an adequate amount of network capital. In this case, the perceived resonance be- 
tween spatial attitudes and possibilities may be interpreted as an aspect of spatial coherence even though many (presumably most) possibilities will never be explored (see also Jansson 2009b). The following story of Erik further underscores how the gaining of network capital, although we are here dealing with very moderate amounts, entails a glocal re-composition of lived space.

Erik: My daughter got married and my wife was worried: "I don't have any clothes!", but I said "let's have a look on the web". And we could browse through and look at all kinds of dresses and shoes and so on, so I sat there with the Internet and saved all the images that I thought were nice, because she wanted me to do that, and when she came home she glanced through them... and she was very satisfied. [...] Finally, we got in touch with a woman in Skåne (Southern Sweden) who made her own clothes, evening dresses and so on, in her own design, which we thought was nice, and through email we got exactly the color and size we wanted. It was perfect! [...] But the most funny thing, we thought, were the shoes. We bought them in America! [laughter]

Erik further describes how he could track the exact location of their order through DHL's online system, which revealed that it took two days to transport the shoes from the USA to the city of Karlstad (in the nearby region) and then another eight days to get them delivered to the pick-up spot in Granby. Erik's story expresses a contradictory spatial experience: network capital provides access to a plethora of online spaces of sociability and commerce, engendering an entirely new image of a "world within reach", while it is partly corrupted through the inescapable unevenness of material infrastructures (the well-known "last mile problem" - see Bakardjieva and Williams's article in this special issue). While this condition highlights an enduring problem of spatial incoherence, the most important conclusion from a sustainability perspective is that the access to a networked space of flow makes it easier to carry out rural everyday life - in its traditional as well as in more innovative forms. This suggests that network capital, as opposed to mere network sociality, is a key asset for sustaining the cultural diversity of rural communities in times of mediatization.

\section{(b) The Time-Binding Function of Network Sociality}

My second main point comprises that network sociality in itself attains an important time-binding function, and thus may operate as a social stabilizer under conditions of volatility and uncertainty. In his characterization of network sociality, Andreas Wittel (2001: 66-8) points to a shift from durable to ephemeral relations and from narration to information. Both aspects seem to identify a new temporal regime in which longstanding relationships based on trust, regularity, and shared life biographies are replaced by rapid alterations in loyalty and affection. Similar transitions have been extensively discussed in Zygmunt Bauman's books about liquidity (e.g. Bauman 2000). As Wittel and Bauman argue, networked media hold a great potential to reinforce this new regime of liquidity which also reproduces itself through the ideology of urban nodes (see e.g. Sassen 2001). However, while the hegemonic interpretations of network society (sometimes blatantly 
echoed in critical academic discourse) depict it as an increasingly flat space of immediacy (or amnesia), the actual appropriation of networking technologies in everyday life is a much more multi-faceted process; one in which the desire to nourish one's life biography is often just as significant as, or even stronger than, the wish to expand one's network.

In the early 1990s, Silverstone and Hirsch (1992) presented their ground breaking ethnographic study of how the uses of television and other electronic devices where shaped through, as well as shaping, the "moral economy" of the household - a concept pointing to the enduring, largely inherited normative structures through which economic and other practices are socially regulated. Similarly, scholars like Bakardjieva (2005) have more recently pointed out how computer technologies are incorporated in household time-spaces and how online virtual sociality may not only provide an expanding network, but also enhance existing bonds of community and transform anonymous sociality into more intimate and enduring forms of togetherness. Bakardjieva (ibid: 176-80) mentions how interviewees who had gone through what we may call "fateful moments" in their life biographies (Goffman 1967; Giddens 1991) - facing a particular medical diagnosis or trying to cope with the disruptive experience of being an immigrant - could find support and a new meaning through online contacts that were anonymous from the very beginning.

In a similar manner, it is obvious that the online practices among those of my interviewees who use social networking platforms on a regular basis are both routinized and attached to the narrative of the self. They are thus time-binding in a double sense. Richard, who after many years of dwelling in other parts of Sweden moved back to Granby to live in the inherited family house with his partner, describes how MySpace and Facebook now help him tying together the time-space slices of his life biography - while simultaneously opening the gates for new acquaintances on a global level.

Richard: I use MySpace because it's fun, and for meeting friends and listening to their music. They are everywhere from Istanbul to Japan. It's a little exciting. [...] I have one page of my own, and then I have one page with each band, and then all members have their pages. [...] In the beginning, I was online on a daily basis but now it's perhaps twice a week. Now I'm also forced to be part of Facebook... it fills a little function because I can talk to old friends, and post some sentences, chat a little. One of the old members of the band who is in Stockholm, I chatted with yesterday. [...] And we are also a group who has created a community on Facebook with the name Young in Storvik 1965-75 with nostalgic pictures and so on.

While Richard's networking practices are largely interest driven and circle around music and culture, they also represent an ongoing ambition to create continuity $-\mathrm{a}$ meaningful narrative of the self. His statement provides an interesting illustration of how different temporal layers intersect through online spaces of practice and thereby contribute to a particular biographical rhythmicity and resonance within everyday life. This sense of continuity and resonance is important to the establishment of ontological security and thus an important groundwork for coping 
with uncertainty and social change (conditions that often characterize rural areas to a much greater extent than what is suggested by popular clichés of slow-paced traditional communities). Even though the community of Granby is currently undergoing a period of mostly positive social transformations, the daily incorporation of glocal networking routines and rituals must be regarded as a means of coping with future ruptures and threats to the lifeworld.

\section{Conclusions}

This study has looked at one particular aspect of mediatization; the ways in which new ICT networks affect the spatial coherence of a "global countryside". If we reconsider Michael Wood's (2007) ten forces for the making of a global countryside that I presented in the beginning of this article, we may easily envision spaces of fragmentation and rupture where the inflow of competing interests and experiences, paired with the uneven distribution of resources, threaten the sustainability of small communities. While new ICT networks are clearly not the sole solution to the negative side effects of globalization, this article has illuminated their socially stabilizing and intermediary potential. Applying a Lefebvrian model of rural media space, I have argued that new networks attain great symbolic significance for small communities in times of globalization - greater than in urban areas, where media infrastructure is not as scarce a resource. In the empirical case of Granby, new ICT networks have contributed to a more coherent narrative of positive structural change where one of the potential causes of incoherence has been (and to some extent still is) the limited reach of these networks themselves. This situation underscores the multilayered character of mediatization as a process of social re-emebedding.

I have also argued that networking resources in general and social media in particular are a potential key to the socio-cultural sustainability of countryside communities, as the interest driven interaction patterns of these resources comply with the intersectional and narrative character of identity creation. Networked interaction sustains the production of glocally defined life stories, and thus contributes to the socio-cultural diversity of the countryside (if other spatial means of attraction are also at hand, that is to say). In this context I have particularly pointed to the analytical potential of John Urry's (2007) concept of network capital, through which we may conceive of the networked production of a global countryside as a dynamic interplay between community and network sociality. The possession of network capital provides a sense of connectivity as well as direct networking abilities. This means that network capital contributes to the coherence of perceived, conceived and lived spaces. An important future path of study would be to establish a more exact understanding of how the distribution of network capital interacts with concrete patterns of mobility among countryside populations - locally and globally. Furthermore, it is important to analyze to what extent the possession 
of network capital, as this study indicates, contributes to making the "global countryside" a "cosmopolitan countryside".

André Jansson is a professor in Media and Communication Studies at Karlstad University, Sweden. He currently leads two research projects: "Rural Networking/Networking the Rural" together with Magnus Andersson (funded by FORMAS), and "Secure Spaces: Media, Consumption and Social Surveillance" together with Miuyase Christensen (funded by Riksbankens Jubileumsfond).

E-mail: andre.jansson@,kau.se

\section{Notes}

1 This study is part of the ongoing project Rural Networking/Networking the Rural, financed by The Swedish Research Council for Environment, Agricultural Sciences and Spatial Planning.

2 Before and during the research period, I have spent several week-long stays in the community. This enabled me to gather a broad understanding of people's life conditions through observations and everyday conversations, which I have followed up in the interviews.

\section{References}

Bakardjieva, Maria (2005): Internet Society: The Internet in Everyday Life, London: Sage.

Bauman, Zygmunt (2000): Liquid Modernity. Cambridge: Polity Press.

Bourdieu, Pierre (1979/1984): Distinction: A Social Critique of the Judgement of Taste, London: Routledge.

Bunce, Michael (1994): The Countryside Ideal: Anglo-American Images of Landscape, London: Routledge.

Cresswell, Tim (2006): On the Move: Mobility in the Modern Western World, London: Routledge.

Cruickshank, Jørn A. (2009): “A Play for Rurality - Modernization versus Local Autonomy”, Journal of Rural Studies, 25, 98-107.

Fish, Robert (2005): "Mobile Viewers: Media Producers and the Televisual Tourist", David Crouch, Rhona Jackson \& Felix Thompson (eds): The Media and the Tourist Imagination: Converging Cultures, London: Routledge.

Giddens, Anthony (1991): Modernity and Self-Identity: Self and Society in the Late Modern Age, Cambridge: Polity Press.

Goffman, Erving (1967): Interaction Ritual: Essays on Face-to-Face Behaviour, London: Allen Lane, Penguin Press.

Halfacree, Keith (2006): "Rural Space: Constructing A Three-Fold Architecture", Paul Cloke, Terry Marsden \& Patrick H. Mooney (eds): Handbook of Rural Studies, London: Sage.

- (2007): “Trial By Space For A 'Radical Turn': Introducing Alternative Localities, Representations and Lives', Journal of Rural Studies, 23, 125-141.

Jansson, André (2009a): "Medierat centrum-marginaliserad idyll: Svenskarnas föreställningar om stad och land", Sören Holmberg \& Lennart Weibull (eds): Svensk höst: Trettiotre kapitel om politik, medier och samhälle, Göteborg: The SOM Institute.

- (2009b): "Mobile Belongings: Texturation and Stratification in Mediatization Processes", Lundby, Knut (ed.): Mediatization: Concept, Changes, Consequences, New York: Peter Lang. 
Jansson, André \& Jesper Falkheimer (2006): “Towards a Geography of Communication”, Jesper Falkheimer \& André Jansson (eds.) Geographies of Communication, Göteborg: Nordicom.

Juska, Arunas (2007): "Discourses on Rurality in Post-Socialist News Media: The Case of Lithuania's Leading Daily 'Lietuvos Rytas' (1991-2004)”, Journal of Rural Studies, 23, 238-253.

Kline, Ronald R. (2000): Consumers in the Country: Technology and Social Change in Rural America, Baltimore: Johns Hopkins University Press.

Lefebvre, Henri (1974/1991): The production of space. Oxford: Blackwell.

Lundby, Knut (2009): “Introduction: 'Mediatization' as Key”, Knut Lundby (ed.): Mediatization: Concept, Changes, Consequences, New York: Peter Lang.

McKenzie, Stephen (2004): Social Sustainability: Towards Some Definitions, Magill: Working Paper No 27, Hawke Research Institute.

Moores, Shaun (2004): "The Doubling of Place: Electronic Media, Time-Space Arrangements and Social Relationships", Nick Couldry \& Anna McCarthy (eds): Mediaspace: Place, Scale and Culture in a Media Age, London: Routledge.

Moores, Shaun (2008): "Conceptualizing Place in A World of Flows", Andreas Hepp, Friedrich Krotz, Shaun Moores \& Carsten Winter (eds): Connectivity, Networks and Flows: Conceptualizing Contemporary Communications, Cresskill, NJ: Hampton Press.

Morley, David (2007): Media, Modernity and Technology: The Geography of the New, London: Routledge.

Park, Sam Ock (2004): "Knowledge, Networks and Regional Development in the Periphery in the Internet Era", Progress in Human Geography, 28:3, 283-286.

Putnam, Robert D. (2000): Bowling Alone: The Collapse and Revival of American Community, New York, NY: Simon \& Schuster.

Sassen, Saskia (2001): The Global City: New York, London, Tokyo (Second Edition), Princeton, N J: Princeton University Press.

Scott, Kathryn, Julie Park \& Chris Cocklin (2000): "From 'Sustainable Rural Communities' to 'Social Sustainability': Giving Voice to Diversity in Mangakahia Valley, New Zealand', Journal of Rural Studies, 16:4, 433-446.

Scannell, Paddy (2006): Radio, Television and Modern Life: A Phenomenological Approach, Oxford: Blackwell.

Short, Brian (2006): "Idyllic Ruralities", Paul Cloke, Terry Marsden \& Patrick Mooney (eds): Handbook of Rural Studies, London: Sage.

Silverstone, Roger, Eric Hirsch \& David Morley (1992): "Information and Communication Technologies and the Moral Economy of the Household", Roger Silverstone \& Eric Hirsch (eds): Consuming Technologies: Media and Information in Domestic Spaces, London: Routledge.

Tomlinson, John (1999): Globalization and Culture, Cambridge, UK: Polity Press.

— (2001): Instant access: Some cultural implications of 'globalising' Technologies, University of Copenhagen: Global Media Cultures Working Paper No 13.

(2008): "YYour Life - To Go': The Cultural Impact of New Media Technologies", Andreas Hepp, Friedrich Krotz, Shaun Moores \& Carsten Winter (eds): Connectivity, Networks and Flows: Conceptualizing Contemporary Communications, Cresskill, NJ: Hampton Press.

Tönnies, Ferdinand (1887/2001): Community and Civil Society, Cambridge: Cambridge University Press.

Urry, John (2003): “Social Networks, Travel and Talk”, British Journal of Sociology, 54:2, 155175.

(2007): Mobilities, Cambridge: Polity Press.

Wittel, Andreas (2001): "Toward a Network Sociality", Theory, Culture \& Society, 18:6, 51-76.

Woods, Michael (2007): "Engaging the Global Countryside: Globalization, Hybridity and the Reconstitution of Rural Place", Progress in Human Geography, 31:4, 485-507.

Zimmerman Umble, Diane (2003): "Sinful Network or Divine Service: Competing Meanings of the Telephone in Amish Country", Lisa Gitelman \& Geoffrey B. Pingree (eds): New Media 1740-1915. Cambridge, MA: MIT Press. 